\title{
Toxic Effects of Mercury on the Cardiovascular and Central Nervous Systems
}

\author{
Bruna Fernandes Azevedo, ${ }^{1}$ Lorena Barros Furieri, ${ }^{1}$ Franck Maciel Peçanha, ${ }^{2}$ \\ Giulia Alessandra Wiggers, ${ }^{3}$ Paula Frizera Vassallo, ${ }^{4}$ \\ Maylla Ronacher Simões, ${ }^{1}$ Jonaina Fiorim, ${ }^{1}$ Priscila Rossi de Batista, ${ }^{1}$ \\ Mirian Fioresi, ${ }^{5}$ Luciana Rossoni, ${ }^{6}$ Ivanita Stefanon, ${ }^{1}$ \\ María Jesus Alonso, ${ }^{7}$ Mercedes Salaices, ${ }^{8}$ and Dalton Valentim Vassallo ${ }^{1,9}$ \\ ${ }^{1}$ Programa de Pós-Graduação em Ciências Fisiológicas, Universidade Federal do Espírito Santo, 29042-755 Vitória, ES, Brazil \\ ${ }^{2}$ Curso de Fisioterapia, Universidade Federal do Pampa, 97050-460 Uruguaiana, RS, Brazil \\ ${ }^{3}$ Programa de Pós-Graduação em Bioquímica, Universidade Federal do Pampa, 97050-460 Uruguaiana, RS, Brazil \\ ${ }^{4}$ Hospital Universitário Cassiano Antônio de Morais, Universidade Federal do Espírito Santo, 29040-091 Vitória, ES, Brazil \\ ${ }^{5}$ Departamento de Enfermagem, Universidade Federal do Espírito Santo, 29040-090 Vitória, ES, Brazil \\ ${ }^{6}$ Departamento de Fisiologia e Biofísica, Universidade de São Paulo, 05508-900 São Paulo, SP, Brazil \\ ${ }^{7}$ Departamento de Fisiologia, Universidad Rey Juan Carlos, 28922 Alcorcón, Spain \\ ${ }^{8}$ Departamento de Farmacología, Universidad Autónoma de Madrid, 28029 Madrid, Spain \\ ${ }^{9}$ Escola Superior de Ciências da Santa Casa de Misericórdia de Vitória, EMESCAM, 29045-402 Vitória, ES, Brazil
}

Correspondence should be addressed to Bruna Fernandes Azevedo, brunafernandes.azevedo@gmail.com

Received 3 April 2012; Accepted 15 May 2012

Academic Editor: Marcelo Farina

Copyright (C) 2012 Bruna Fernandes Azevedo et al. This is an open access article distributed under the Creative Commons Attribution License, which permits unrestricted use, distribution, and reproduction in any medium, provided the original work is properly cited.

\begin{abstract}
Environmental contamination has exposed humans to various metal agents, including mercury. This exposure is more common than expected, and the health consequences of such exposure remain unclear. For many years, mercury was used in a wide variety of human activities, and now, exposure to this metal from both natural and artificial sources is significantly increasing. Many studies show that high exposure to mercury induces changes in the central nervous system, potentially resulting in irritability, fatigue, behavioral changes, tremors, headaches, hearing and cognitive loss, dysarthria, incoordination, hallucinations, and death. In the cardiovascular system, mercury induces hypertension in humans and animals that has wide-ranging consequences, including alterations in endothelial function. The results described in this paper indicate that mercury exposure, even at low doses, affects endothelial and cardiovascular function. As a result, the reference values defining the limits for the absence of danger should be reduced.
\end{abstract}

\section{History}

More than 2500 A.C., the prehistoric man used the cinabrio (mercury sulfide), due to its red-gold color, to draw on cave walls and perform face painting. Subsequently, mercury has been used in the amalgamation (direct burning of metallic mercury on the gravel, promoting the separation of gold), in photography and as an antiseptic in the treatment of syphilis $[1,2]$.

Exposure to mercury brought harmful effects to health of humans, but changes resulting from human exposure to mercury only called the attention of the scientific society after the accidents in Japan and Iraq [3]. In Japan, a serious accident occurred resulting from the deposition of industrial waste with large quantities of mercury in the Minamata Bay. Mercury was then ingested by human through fish intake, thus triggering signs and symptoms such as ataxia, speech impairment, visual field constriction, sensory disturbance, deafness, blindness, tremors, involuntary movements, mental retardation, coma, and death. Infants whose mothers were infected developed mental retardation, peripheral neuropathy, cerebral palsy, and blindness. These changes became 
known as Minamata disease or Russell-Hunter syndrome $[4,5]$. In Iraq, mercury poisoning occurred in 1971 when wheat grains were treated with fungicides containing organic mercury. This poisoning killed over 500 people who ate bread made with contaminated wheat $[6,7]$.

\section{Mercury Characteristics}

Mercury is characterized as a highly malleable liquid at normal temperature and pressure [8]. Its name is derived from the Latin word hydrargyrum, meaning metal that resembles liquid silver [8]. Mercury is classified into three main groups: elemental mercury, inorganic mercury, and organic mercury. Mercury exists in several forms: inorganic mercury, among which There have been the metallic mercury and mercury vapor $\left(\mathrm{Hg}^{0}\right)$ and mercurous mercury $\left(\mathrm{Hg}^{+}\right)$or mercuric mercury $\left(\mathrm{Hg}^{++}\right)$salts; organic mercury, also called organometallic, which results from a covalent bond between mercury and a carbon atom of an organic functional group such as a methyl, ethyl, or phenyl group. The biological behavior, pharmacokinetics, and clinical significance of the various forms of mercury vary according to its chemical structure [3].

\subsection{Inorganic Mercury Compounds}

2.1.1. Elemental Mercury or Metalic Mercury Compounds. In its liquid form, the elemental mercury $\left(\mathrm{Hg}^{0}\right)$ is poorly absorbed and presents little health risk. However, in the vapor form, metallic mercury is readily absorbed through the lungs and can produce body damage [9-11]. Because of its soluble characteristics, elemental mercury is highly diffusible and is able to pass through cell membranes as well as the blood-brain and placental barriers to reach target organs. Once in the bloodstream, mercury undergoes catalase and peroxidase-mediated oxidation in red blood cells and tissues and is transformed into inorganic mercuric mercury $\left(\mathrm{Hg}^{++}\right)$ and mercurous mercury $\left(\mathrm{Hg}^{+}\right)$, a process that limits its absorption $[9,12]$. Inorganic mercury has low lipophilicity and thus has a limited ability to cross cell membranes [9].

Elemental mercury is used in thermometers and sphygmomanometers because of its uniform volumetric expansion, high surface tension, and lack of vitreous adherence to surfaces. Low electrical resistance and high thermal conductivity allow metallic mercury to be used in electrical and electronic materials. Because of its high oxidation power, metallic mercury is used in electrochemical operations in the chlorine and soda industries. Metallic mercury is also used in metallurgy, mining, and dentistry because of the easy amalgam formation with other metals. In addition, gold extraction with archaic and dangerous methods predispose miners to mercury poisoning. The burning of metallic mercury on the gravel promotes the separation of gold, a process called amalgamation, which causes emission of large amounts of mercury vapor that is inhaled immediately by the miner, since they do not use appropriate personal protective equipment $[13,14]$.
Occupational exposure to mercury vapor and the release of mercury from or during removal of amalgam dental fillings increase its blood and plasma concentration $[15,16]$ After exposure, blood concentrations attain $18 \mathrm{nmol} / \mathrm{L}$ [15], and after exposure to dental and removal of amalgam fillings plasma concentrations attain $5 \mathrm{nmol} / \mathrm{L}$ [17]. Occupational exposure also affects central nervous system [15] and amalgam tooth fillings impair sheep kidney function [18]. However, toxicological consequences are still a matter of debate [3, 19-23].

2.1.2. Mercurous Mercury and Mercuric Mercury Compounds. The mercurous mercury in the form of mercurous chloride $\left(\mathrm{Hg}_{2} \mathrm{Cl}_{2}\right)$ is little absorbed in the body. It is believed that in the body the form of metallic mercury is changed to elemental mercury and mercuric mercury [24].

Mercuric mercury compounds, such as mercury salts, result from the combination of mercury with chlorine, sulfur, or oxygen. Mercuric mercury can be found in different states when combined with other chemical elements, including mercuric chloride $\left(\mathrm{HgCl}_{2}\right)$, which is highly toxic and corrosive; mercury sulfide ( $\mathrm{HgS}$ ), which is often used as a pigment in paints due to its red color; mercury fulminate $\left(\mathrm{Hg}(\mathrm{CNO})_{2}\right)$, which is used as an explosive detonator [8, 25]. Among the mercuric mercury compounds, mercuric chloride $\left(\mathrm{HgCl}_{2}\right)$ calls the attention. It was used as a preservative for development of photographic film and has been ingested accidentally or as a suicide measure [26]. As elemental mercury, the mercuric mercury in the blood stream binds to sulfhydryl groups on erythrocytes, glutathione, or metallothionein or is transported suspended in plasma [27]. Mercuric mercury accumulates in placenta, fetal tissues, and amniotic fluid, but it does not cross the bloodbrain barrier efficiently [28]. Evidence exists showing the transport of mercuric mercury via one or more amino acid transporters [29]. Evidence also shows that the accumulation in the brain occurs through its binding to cysteine [24].

In the cardiovascular system, acute inorganic mercury exposition in vivo promotes reduction of myocardial force development [30] and inhibited myosin ATPase activity [31]. Chronic exposure increases vascular resistance and induces hypertension [32-34]. Numerous studies have also revealed that mercury generates oxygen free radicals mainly by activation of NAPHoxidase $[35,36]$.

2.2. Organic Mercury. Organic mercury compounds, also called organometallic, result from a covalent bond between mercury and the carbon [8] atom of an organic functional group such as a methyl, ethyl, or phenyl group. Methylmercury $\left(\mathrm{CH}_{3} \mathrm{Hg}^{+}\right)$is by far the most common form of organic $\mathrm{Hg}$ to which humans and animals are exposed. $\mathrm{CH}_{3} \mathrm{Hg}^{+}$in the environment is predominantly formed by methylation of inorganic mercuric ions by microorganisms present in soil and water [37-39]. The expression methylmercury monomethylmercurial is used to denote compounds that contain the cation methylmercury $\left(\mathrm{CH}_{3} \mathrm{Hg}^{+}\right)$. Some of these compounds were used as pesticides and had medical applications as antiseptics and diuretics. 
The organomercury antiseptics still used are Merthiolate, Bacteran, and Thimerosal [40].

Thimerosal is an organomercurial compound that since 1930 has been widely used as a preservative in biological material such as vaccines and serums used to prevent microbiological growth [41]. Thimerosal is metabolized in the human body and degraded into ethylmercury and thiosalicylate. The chemical difference between these compounds is an important determinant of their toxicity $[42,43]$.

\section{Forms of Mercury Exposure}

Mercury is now considered an environmental pollutant of high risk to public health because of its high toxicity and mobility in ecosystems $[11,44]$. Exposure to mercury can occur from both natural and artificial sources. Human activities that can result in mercury exposure include the burning of fossil fuels, chlor-alkali industries, mining, the burning of waste, and the use of coal and petroleum [10, 40, 45].

More natural sources of mercury include volcanic activity, earthquakes, erosion, and the volatilization of mercury present in the marine environment and vegetation [10, 4648]. Mercury emitted both naturally or as a result of human activity is primarily found as inorganic metal vapor $\left(\mathrm{Hg}^{0}\right)$ [49]. Among the natural sources of mercury, the largest emissions are from the degassing of the earth's crust. More than five tons of mercury is estimated to be released into the sea every year as a result of erosion and geochemical cycles [50].

Mercury contaminates the environment through a cycle involving the initial emission, the subsequent atmospheric circulation of the vapor form, and the eventual return of mercury to the land and water via precipitation (Figure 3) [46]. The emission of mercury is an important part of this cycle of contamination and can occur through natural processes or as a result of human activities, as mentioned above [48].

Mercury present in seas and rivers after methylation can contaminate fish $[51,52]$. The consumption of fish contaminated with mercury is a major source of mercury exposure in the Amazon basin. Studies show that the concentration of mercury in the muscles of fish that are widely consumed in the Amazon region are greater than the limit set by WHO (World Health Organization) as safe for human consumption $(0.5 \mathrm{~g} / \mathrm{kg})[4,10]$.

\section{Transport and Elimination of Mercury}

Inhaled elemental mercury vapor, for example, is readily absorbed through mucous membranes and the lung and is rapidly oxidized but not as quickly as to prevent the deposition of considerable amount in the brain [54]. Methylmercury is easily absorbed through the gut, and it is deposited in most tissue but does not cross the bloodbrain barrier as efficiently as elemental mercury. However, to enter the brain, it is progressively demethylated to elemental mercury (Figure 2) [24]. Mercury salts, in contrast, tend to be insoluble, relatively stable, and hardly absorbed.
Then, toxicity for man varies depending on the form of mercury, dose, and rate of exposure. The target organ for inhalted mercury vapor is primarily the brain [24]. Mercurous and mercury salts especially damage the lining of the intestine and kidneys [5], and as methyl mercury, it is widely distributed throughout the body (Figure 1) [24]. Toxicity varies with dosage; a large acute exposure to elemental mercury vapor induces severe pneumonia, which in extreme cases can be fatal [24]. Low level of chronic exposure to elemental or other forms of mercury induces more subtle symptoms and clinical findings [3].

Oxidized mercury binds strongly to SH groups; this reaction can inactivate enzymes, lead to tissue damage and interfere with various metabolic processes [55-57]. Ingested methylmercury is almost completely absorbed and transported into the bloodstream [10]. Methylmercury enters cells mainly by forming a complex with L-cysteine and homocysteine and is eliminated in conjunction with glutathione [58]. After absorption, it is distributed primarily to the central nervous system and kidneys. Methylmercury elimination usually occurs in the urine and feces [59].

\section{Doses of Mercury and Safety Legislation}

The chemical form of mercury in the air affects its time of permanence and its dispersion in the atmosphere. The elemental mercury form can persist for more than four years in the air, while its compounds are deposited in a short time at locations near their origin. In the northern hemisphere, their average concentration in the atmosphere is estimated at $2 \mathrm{ng} / \mathrm{m}^{3}$ and in the southern hemisphere is less than $1 \mathrm{ng} / \mathrm{m}^{3}$. In urban areas, there is a great variability of these concentrations being found up to $67 \mathrm{ng} / \mathrm{m}^{3}$ with a mean of $11 \mathrm{ng} / \mathrm{m}^{3}$ in Japan [53]. FUNASA (Fundação Nacional de Saúde) standards of mercury in the air consider a mean of $1 \mathrm{ng} / \mathrm{m}^{3}$ in the period of one year [60].

In 2004, the Joint FAO (Food and Agriculture Organization of the United National)/WHO Expert Committee on Food Additives (JECFA) established that the safe concentration of methylmercury intake, without the appearance of neurological disorders, is $1.6 \mathrm{mg} / \mathrm{kg}$ of body weight. However, in 2006, JECFA stated that this concentration is not safe for intrauterine exposure, because fetuses are more sensitive to the onset of neurological disorders after exposure to methylmercury [61].

Currently, the general population is exposed to mercury by the following main sources: the consumption of contaminated fish, the use and manipulation of dental amalgam, thimerosal contained in vaccines, workers in industries of chlorine, caustic soda, miners, and workers in industries of fluorescent lamps $[62,63]$. Each of these sources of exposure contains specific toxicological characteristics [64].

In Brazil, the rules for vaccination of the Ministry of Health, published in June 2001, shows that thimerosal is used in many vaccines. These vaccines prevent flu (influenza vaccine), rabies (rabies vaccine), infection with meningococcus serogroup b, and hepatitis B [65].

The US Environmental Protection Agency's recommended a reference blood concentration of mercury to be 


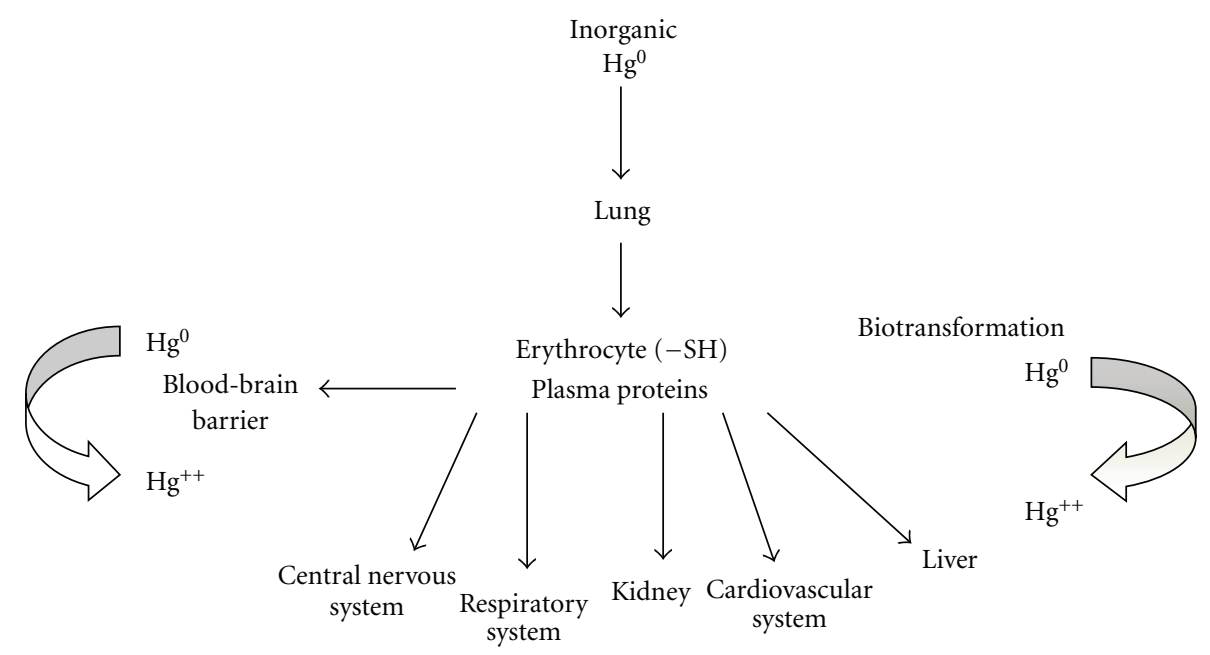

FIGURE 1: Scheme showing the entry of elemental mercury in organisms and their distribution in different organs.

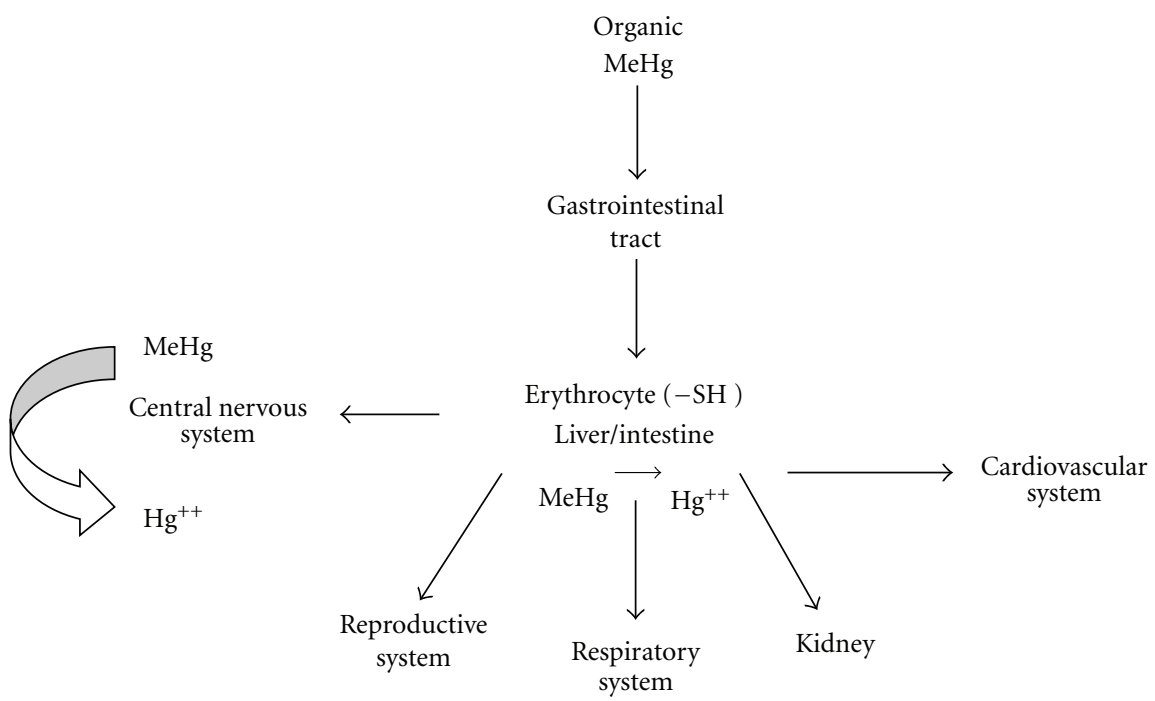

FIGURE 2: Scheme showing the entry of organic mercury in organisms and their distribution in different organs.

$5.8 \mathrm{ng} / \mathrm{mL}$; concentrations below this level are considered to be safe $[66,67]$. Some studies have reported that the blood mercury concentration in the control population is approximately $1 \mathrm{ng} / \mathrm{mL}$. On the other hand, levels of $7-10 \mathrm{ng} / \mathrm{mL}$ have been reported in workers exposed to mercury or in residents of Guizhou (China), an area that is known to suffer mercury contamination $[68,69]$. In a recent biomonitoring study in New York City, the blood mercury concentration was found to be $2.73 \mathrm{ng} / \mathrm{mL}$, and levels reached $5.65 \mathrm{ng} / \mathrm{mL}$ in adults that consumed fish regularly [70].

WHO [10] states that an allowable concentration of mercury in human hair is less than $6 \mu \mathrm{g} / \mathrm{g}$. In the Amazon basin, where fish is the main source of dietary protein, mercury concentrations in hair reached up to $150 \mu \mathrm{g} / \mathrm{g}$. Furthermore, only two of 40 cities studied have average mercury concentrations below the recommended amount $[10,71]$. In individuals who have amalgam, the daily release of mercury amalgam is approximately $4-5 \mu \mathrm{g} / \mathrm{day}$, and a positive correlation exists between the blood concentration of mercury and the number of amalgams. It is estimated that each dental amalgam releases 3-17 $\mu$ g mercury vapor per day and that the blood concentration of mercury after removal of the restoration can reach $5 \mathrm{nmol} / \mathrm{L}$ [72-74]. However, even at concentrations below recommended levels, there is strong evidence that exposure to ethyl mercury, the major component of thimerosal, is associated with the onset of neurological and heart disorders in children [75].

In the following sections, we will describe results obtained from animals with chronic and acute exposure to mercury. Some of these studies were performed with mercury exposure protocols that led to blood concentrations slightly above the reference values. Nevertheless, these concentrations could be easily found in exposed populations and may even be considered low when compared with concentrations in humans who consume large amounts of fish or who live in areas contaminated with mercury. 


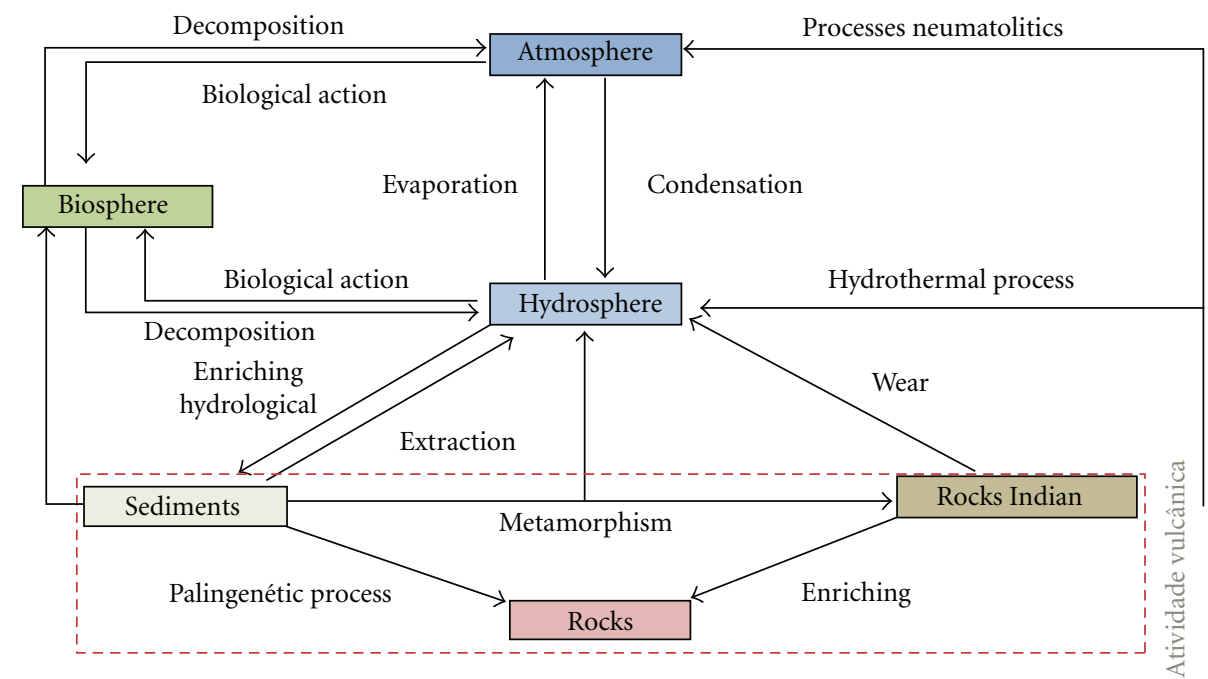

Figure 3: Cycle of mercury in the environment. Modified from Azevedo and Chasin 2003 [53]. Scheme demonstrating constant flow of mercury compounds in the hydrosphere, lithosphere, atmosphere, and biosphere.

\section{Effect of Mercury on the Central Nervous System (CNS)}

Among the compounds of mercury, the methylmercury is primarily responsible for the neurological alterations present in humans and experimental animals. It is believed that the mechanisms are related to the toxic increase in reactive oxygen species (ROS). Oxidative stress is associated with the etiology of neurodegenerative diseases such as amyotrophic lateral sclerosis, Parkinson's disease, and Alzheimer's disease $[54,55]$, but these mechanisms have yet to be fully recognized.

Reinforcing the hypothesis that the majority of injuries caused by methylmercury ( $\mathrm{MeHg}$ ) in the central nervous system are related to its ability to increase reactive oxygen species, Zhang et al. (2009) [20] reported that after pretreatment of bovine cells with pyrroloquinoline quinone (PQQ), an antioxidant, the cytotoxicity induced by $\mathrm{MeHg}$ is significantly attenuated. PQQ reduces the percentage of apoptotic cells, decreased significantly ROS production, suppressed lipid peroxidation, and increased antioxidant enzyme activity in cells exposed to MeHg. Furthermore, the protective effects elicited by an antioxidant (ebselen) strengthen the idea that seleno-organic compounds represent promising approaches to neutralize $\mathrm{MeHg}$-induced neurotoxicity [19].

Studies also demonstrate that mercury has the ability to reduce the number of neuron and cytoarchitecture in individuals with prenatal exposure to mercury $[76,77]$. In animal models, some of these symptoms are reproduced. Low-dose prenatal exposure to methylmercury during 10 gestational days impairs motor and mnemonic function in adult mice [23]. This hypothesis is supported by studies that describe methylmercury inhibition of cell division and migration both "in vivo" and "in vitro" [76-78].
In addition, because of its high affinity for sulfhydryl groups in tubulin, methylmercury inhibits the organization of microtubules that are important in CNS development [79-81]. The binding to SH groups also interferes with the intracellular signaling of multiple receptors (e.g., muscarinic, nicotinic, and dopaminergic) and promotes the blockade of $\mathrm{Ca}^{++}$channels in neurons $[82,83]$. In addition, inorganic mercury has the ability to increase the permeability of chloride channels of GABA A receptors in the dorsal root ganglion, which is associated with neuronal hyperpolarization [84].

Corroborating these findings, the study conducted by Maia et al., (2010) [21] demonstrates that the poisoning by methylmercury changes the nitrergic activities of adult mice, and the predominance of alterations may be related to different locations. Besides increasing the nitrergic activity methylmercury and mercuric chloride also have the ability to increase the release of neurotransmitters such as acetylcholine, dopamine, norepinephrine, and serotonin. Similar findings have also been reported to be a mechanism implicated in the effects of methylmercury and $\mathrm{HgCl}_{2}$ on the central nervous system function [85-89].

Halbach et al. [90] studied a correlation in Iraqi children between the level of maternal exposure to methylmercury during pregnancy and psychomotor retardation. SandborghEnglund et al. [91] corroborated this finding in children from the Faroe Islands; they found that children exposed to mercury in the prenatal period had defects in attention, memory, language, and motor function. In addition, exposure to methylmercury in pregnant women or early childhood leads to changes in the CNS development of the fetus or child, respectively [50, 92, 93]. Thereupon, changes caused by mercury poisoning result in significant clinical deficit in motor skills, coordination, and general activity rate of cognitive and psychological disorders [23]. 


\section{Effect of Mercury on the Cardiovascular System}

For decades, the toxic effects of mercury were associated mainly with the central nervous system; however, inorganic mercury also produces profound cardiotoxicity [94-99]. Halbach and collaborators [100] showed that mercury concentrations in hair reached up to $150 \mu \mathrm{g} / \mathrm{g}$ in populations living in the Amazon basin. Furthermore, nearly all of the inhabitants of 40 cities studied have blood concentrations above the reference values. In this population, it has been demonstrated that exposure to mercury by frequent consumption of fish has a strong positive correlation with increased arterial blood pressure [101]. Other studies also correlate mercury exposure with increased risk of hypertension, myocardial infarction, coronary dysfunction, and atherosclerosis [102-105]. Data presented by Yoshizawa et al. [106] showed that mercury exposure was associated with the progression of atherosclerosis and an increased risk of developing cardiovascular disease. Houston [107] followed patients for approximately 13.9 years and found an association between the concentration of mercury in the hair and the risk of developing cardiovascular events or dying from cardiovascular disease and other causes.

Mercury levels are predictors of the levels of oxidized low-density lipoprotein (LDL) [106]. Oxidized LDL particles are frequently found in atherosclerotic lesions and are associated with the development of atherosclerotic disease $[107,108]$ and acute coronary insufficiency [109]. Another mechanism by which mercury exerts toxic effects on the cardiovascular system is through the inactivation of the "paraoxonase" [110], an enzyme that slows the LDL oxidation process and that has an important antiatherosclerotic action [101].

The mechanism by which mercury produces toxic effects on the cardiovascular system is not fully elucidated, but this mechanism is believed to involve an increase in oxidative stress. Exposure to mercury increases the production of free radicals, potentially because of the role of mercury in the Fenton reaction [111-113] and a reduction in the activity of antioxidant enzymes, such as glutathione peroxidase. The $\mathrm{MeHg}$ reaction with the glutathione peroxidase occurs via thiol (-SH) and/or selenol (-SeH) groups from endogenous molecules [114]. Even though there are 4 of glutathione molecules containing selene in their active sites, only the cytoplasmic glutathione peroxidase 1 ( GPx 1) changes hydrogen peroxide to water $[115,116]$.

The reduction in glutathione peroxidase with seleniumdependent activity is the result of the decreased bioavailability of selenium, a molecule that is required for enzymatic activity [117-119]. The high affinity of mercury to the thiol group can lead to decreased glutathione peroxidase selenium-dependent activity. Other antioxidant enzymes which participate against reactive oxygen species due to mercury intoxication are catalase and superoxide dismutase. The increment of ROS and reduction of the antioxidant activity increase the risk of developing cardiovascular disease $[118,120,121]$.
Sherwani et al. (2011) [122] showed that MeHg has the capacity to induce phospholipase D (PLD) activation through oxidative stress and thiol-redox alterations. They investigated the mechanism of the MeHg-induced PLD activation through the upstream regulation by phospholipase $\mathrm{A}_{2}$ $\left(\mathrm{PLA}_{2}\right)$ and lipid oxygenases such as cyclooxygenase (COX) and lipoxygenase (LOX) in the bovine pulmonary artery endothelial cells. Their results showed that $\mathrm{MeHg}$ significantly activates both $\mathrm{PLA}_{2}$ and PLD. MeHg also induces the formation of COX- and LOX-catalyzed eicosanoids in endothelial cells.

Cardiovascular changes resulting from mercury poisoning are also described in animal models. However, the mechanism involved in the effects of mercury on the cardiovascular system is not fully understood but seems to be dependent on both the dose and time of exposure. Raymond and Ralston [123] studied the hemodynamic effects of an intravenous injection of $\mathrm{HgCl}_{2}(5 \mathrm{mg} / \mathrm{kg})$ in rats and observed that mercury produced cardiac diastolic failure and pulmonary hypertension. Moreover, Naganuma et al. [124] reported that acute exposure to $\mathrm{HgCl}_{2}(680 \mathrm{ng} / \mathrm{kg})$ increased blood pressure, heart rate, and vascular reactivity to phenylephrine in rats; this increased reactivity seems to depend on an increased generation of free radicals. Perfused hearts from animals exposed acutely to $\mathrm{HgCl}_{2}$ showed a reduction in left ventricular systolic pressure, heart rate, and atrioventricular conduction delay $[125,126]$.

Our group has found that chronic exposure to low doses of mercury (1st dose $4.6 \mu \mathrm{g} / \mathrm{kg}$ followed by $0.07 \mu \mathrm{g} / \mathrm{kg} /$ day for 30 days, im) attained a blood mercury concentration of approximately $8 \mathrm{ng} / \mathrm{mL}$, a concentration similar to the levels found in exposed humans. This exposure produced a negative inotropic effect in perfused hearts, although increasing myosin ATPase activity. Invivo, arterial or ventricular pressures did not change [127]. The reduction in contractility was explained by alterations in calciumhandling mechanisms; protein expression of SERCA, $\mathrm{Na}^{+}$ $\mathrm{K}^{+}$ATPase (NKA), and sodium/calcium exchanger (NCX) was diminished; phospholamban (PLB) expression was increased; the response to $\beta$-adrenergic stimulation was reduced following mercury exposure $[128,129]$.

The chronic exposure to low concentrations of mercury was also able to induce endothelial dysfunction in resistance and conductance vessels, most likely because of the decreased nitric oxide (NO) bioavailability due to the increased superoxide anion $\left(\mathrm{O}_{2}{ }^{--}\right)$production from NADPH oxidase $[36,130,131]$. This study was evidenced by the following effects of mercury treatment observed in aorta, coronary, and mesenteric arteries: (1) the endotheliumdependent vasodilator response induced by acetylcholine (ACh) was decreased [36, 130]; (2) vasoconstrictor responses to phenylephrine or serotonin were increased, and NO endothelial modulation of these responses was decreased [36, 130, 131]; (3) vascular superoxide anion production, the expression of SOD-2, NOX-1, and NOX-4 (two main isoforms of NADPH oxidase), plasmatic malondialdehyde levels, and plasmatic antioxidant status were all increased $[36,130] ;(4)$ both the superoxide anion scavenger SOD and the NADPH oxidase inhibitor apocynin restored 
the NO endothelial modulation of vasoconstrictor responses and the impaired ACh-induced vasodilatation in vessels from the mercury-treated rats $[36,130]$. We also observed that mercury treatment increased the participation of COX2-derived vasoconstrictor prostanoids in vasoconstrictor responses [132]. Other researchers have also observed a selective loss of NO-mediated vasodilatation with no effect on the EDHF-mediated component of relaxation, implying that chronic mercury exposure selectively impairs the NO pathway as a consequence of oxidative stress, while EDHF is able to maintain endothelium-dependent relaxation at a reduced level [133]. On the other hand, using this low dose of mercury, Blanco-Rivero et al. [134] observed an increase in vasoconstriction responses to electrical field stimulation mediated by alterations of adrenergic and nitrergic function in rat mesenteric arteries. $\mathrm{HgCl}_{2}$ reduced neuronal $\mathrm{NO}$ bioavailability, most likely as a result of reduced nNOS (neuronal nitric oxide synthase) activity and increased $\mathrm{O}_{2}{ }^{-}$ production as well as increased noradrenaline release and vasoconstrictor response. It is important to emphasize, regarding chronic low-dose exposure to mercury for 30 days, that although rats grow normally and have no changes in arterial blood pressure, endothelial function is already blunted affecting vascular reactivity $[36,131]$.

Taken together, these data show that chronic low doses of mercury have an important and deleterious effect on vascular function by reducing NO bioavailability. The degree of severity of mercury exposure is comparable to traditional cardiovascular risk factors, such as hypertension diabetes or hypercholesterolemia. Therefore, mercury could be considered an important risk factor for cardiovascular disease that could play a role in the development of cardiovascular events. The association between mercury exposure and an increased risk of developing cardiovascular and neurological diseases is apparent. Thus, continuous exposure to mercury can be dangerous, and current reference values, once considered to be without risk, should be reevaluated and reduced.

\section{Acknowledgments}

These studies were supported by Grants from CAPES and CNPq/FAPES/FUNCITEC (39767531/07), Brazil and MCINN and MECD (SAF 2009-07201, RD06/0014/0011, and PHB2011-0001-PC) and Banco Santander, Spain. All participants of the group who performed experiments that were used in this paper are listed as authors. Dr. M. Salaices and Dr. M. J. Alonso advised several students of the group during their Doctoral Sandwich Program in the Universidade Autonóma de Madrid, Spain.

\section{References}

[1] L. D. Hylander and M. Meili, "500 Years of mercury production: global annual inventory by region until 2000 and associated emissions," Science of the Total Environment, vol. 304, no. 1-3, pp. 13-27, 2003.

[2] S. Ekino, M. Susa, T. Ninomiya, K. Imamura, and T. Kitamura, "Minamata disease revisited: an update on the acute and chronic manifestations of methyl mercury poisoning,"
Journal of the Neurological Sciences, vol. 262, no. 1-2, pp. 131144, 2007.

[3] R. A. Bernhoft, "Mercury toxicity and treatment: a review of the literature," Journal of Environmental and Public Health, vol. 2012, Article ID 460508, 10 pages, 2012.

[4] M. Gochfeld, "Cases of mercury exposure, bioavailability, and absorption," Ecotoxicology and Environmental Safety, vol. 56, no. 1, pp. 174-179, 2003.

[5] T. Takeuchi, K. Eto, Y. Kinjo, and H. Tokunaga, "Human brain disturbance by methylmercury poisoning, focusing on the long- term effect on brain weight," NeuroToxicology, vol. 17, no. 1, pp. 187-190, 1996.

[6] F. Bakir, S. F. Damluji, and I. Amin Zaki, "Methylmercury poisoning in Iraq: an interuniversity report," Science, vol. 181, no. 4096, pp. 230-241, 1973.

[7] T. W. Clarkson, "Molecular and ionic mimicry of toxic metals," Annual Review of Pharmacology and Toxicology, vol. 33, pp. 545-571, 1993.

[8] HSDB-Hazardous Substances Data Bank, "Mercury," in Toxicology, Occupational Medicine and Environmental Series, 2004, http://toxnet.nlm.nih.gov/.

[9] M. C. Houston, "The role of mercury and cadmium heavy metals in vascular disease, hypertension, coronary heart disease, and myocardial infarction," Alternative Therapies in Health and Medicine, vol. 13, no. 2, pp. S128-S133, 2007.

[10] Agency for Toxic Substances and Disease Registry (ATSDR), Toxicological Profile for Mercury, ATSDR, Public Health Service, US Department of Health and Human Services, Washington, DC, USA, 1999, http://www.atsdr.cdc.gov/toxprofiles /tp46.pdf.

[11] R. C. D. C. M. Mesquita, M. I. M. S. Bueno, W. D. F. Jardim, and W. D. F. Jardim, "Compostos de mercúrio. Revisão de métodos de determinação, tratamento e descarte," Quimica Nova, vol. 23, no. 4, pp. 487-495, 2000.

[12] M. Roulet, M. Lucotte, R. Canuel et al., "Distribution and partition of total mercury in waters of the Tapajos River Basin, Brazilian Amazon," Science of the Total Environment, vol. 213, no. 1-3, pp. 203-211, 1998.

[13] J. O. Nriagu, W. C. Pfeiffer, O. Malm, C. M. Magalhaes De Souza, and G. Mierle, "Mercury pollution in Brazil," Nature, vol. 356, no. 6368, article 389, 1992.

[14] M. H. D. Pestana and M. L. L. Formoso, "Mercury contamination in Lavras do Sul, south Brazil: a legacy from past and recent gold mining," Science of the Total Environment, vol. 307, no. 1-3, pp. 125-140, 2003.

[15] S. Langworth, "Exposure to mercury vapor and impact on health in the dental profession in Sweden," Journal of Dental Research, vol. 76, no. 7, pp. 1397-1404, 1997.

[16] S. Halbach, L. Kremers, H. Willruth et al., "Systemic transfer of mercury from amalgam fillings before and after cessation of emission," Environmental Research, vol. 77, no. 2, pp. 115123, 1998.

[17] L. Björkman, G. Sandborgh-Englund, and J. Ekstrand, "Mercury in saliva and feces after removal of amalgam fillings," Toxicology and Applied Pharmacology, vol. 144, no. 1, pp. 156-162, 1997.

[18] N. D. Boyd, H. Benediktsson, M. J. Vimy, D. E. Hooper, and F. L. Lorscheider, "Mercury from dental "silver" tooth fillings impairs sheep kidney function," American Journal of Physiology, vol. 261, no. 4, pp. R1010-R1014, 1991.

[19] Z. Yin, E. Lee, M. Ni et al., "Methylmercury-induced alterations in astrocyte functions are attenuated by ebselen," NeuroToxicology, vol. 32, no. 3, pp. 291-299, 2011. 
[20] P. Zhang, Y. Xu, J. Sun, X. Li, L. Wang, and L. Jin, "Protection of pyrroloquinoline quinone againts methylmercuryinduced neurotoxicity via reducing oxidative stress," Free Radical Research, vol. 43, no. 3, pp. 224-233, 2009.

[21] C. D. S. F. Maia, V. M. M. Ferreira, R. L. Kahwage et al., "Adult brain nitrergic activity after concomitant prenatal exposure to ethanol and methyl mercury," Acta Histochemica, vol. 112, no. 6, pp. 583-591, 2010.

[22] A. F. Castoldi, N. Onishchenko, C. Johansson et al., "Neurodevelopmental toxicity of methylmercury: laboratory animal data and their contribution to human risk assessment," Regulatory Toxicology and Pharmacology, vol. 51, no. 2, pp. 215-229, 2008.

[23] K. S. Montgomery, J. Mackey, K. Thuett, S. Ginestra, J. L. Bizon, and L. C. Abbott, "Chronic, low-dose prenatal exposure to methylmercury impairs motor and mnemonic function in adult C57/B6 mice," Behavioural Brain Research, vol. 191, no. 1, pp. 55-61, 2008.

[24] T. W. Clarkson, J. B. Vyas, and N. Ballatori, "Mechanisms of mercury disposition in the body," American Journal of Industrial Medicine, vol. 50, no. 10, pp. 757-764, 2007.

[25] R. C. D. C. M. Mesquita, M. I. M. S. Bueno, and W. D. F. Jardim, "Compostos de mercúrio. Revisão de métodos de determinação, tratamento e descarte," Quimica Nova, vol. 23, no. 4 , pp. 487-495, 2000.

[26] D. A. Geier and M. R. Geier, "An assessment of the impact of thimerosal on childhood neurodevelopmental disorders," Pediatric Rehabilitation, vol. 6, no. 2, pp. 97-102, 2003.

[27] N. Ballatori and T. W. Clarkson, "Biliary secretion of glutathione and of glutathione-metal complexes," Fundamental and Applied Toxicology, vol. 5, no. 5, pp. 816-831, 1985.

[28] S. Halbach, S. Vogt, W. Köhler et al., "Blood and urine mercury levels in adult amalgam patients of a randomized controlled trial: interaction of $\mathrm{Hg}$ species in erythrocytes," Environmental Research, vol. 107, no. 1, pp. 69-78, 2008.

[29] P. Grandjean, P. Weihe, R. F. White et al., "Cognitive deficit in 7-year-old children with prenatal exposure to methylmercury," Neurotoxicology and Teratology, vol. 19, no. 6, pp. 417-428, 1997.

[30] D. V. Vassallo, C. M. Moreira, E. M. Oliveira, D. M. Bertollo, and T. C. Veloso, "Effects of mercury on the isolated heart muscle are prevented by DTT and cysteine," Toxicology and Applied Pharmacology, vol. 156, no. 2, pp. 113-118, 1999.

[31] C. M. Moreira, E. M. Oliveira, C. D. Bonan, J. J. F. Sarkis, and D. V. Vassallo, "Effects of mercury on myosin ATPase in the ventricular myocardium of the rat," Comparative Biochemistry and Physiology C, vol. 135, no. 3, pp. 269-275, 2003.

[32] M. Carmignani, P. Boscolo, L. Artese et al., "Renal mechanisms in the cardiovascular effects of chronic exposure to inorganic mercury in rats," British Journal of Industrial Medicine, vol. 49, no. 4, pp. 226-232, 1992.

[33] Y. Wakita, "Hypertension induced by methyl mercury in rats," Toxicology and Applied Pharmacology, vol. 89, no. 1, pp. 144-147, 1987.

[34] M. C. Houston, "The role of mercury and cadmium heavy metals in vascular disease, hypertension, coronary heart disease, and myocardial infarction," Alternative Therapies in Health and Medicine, vol. 13, no. 2, pp. S128-S133, 2007.

[35] L. Massaroni, L. V. Rossoni, S. M. C. Amaral, I. Stefanon, E. M. Oliveira, and D. V. Vassallo, "Haemodynamic and electrophysiological acute toxic effects of mercury in anaesthetized rats and in Langendorff perfused rat hearts," Pharmacological Research, vol. 32, no. 1-2, pp. 27-36, 1995.
[36] L. B. Furieri, M. Fioresi, R. F. R. Junior et al., "Exposure to low mercury concentration in vivo impairs myocardial contractile function," Toxicology and Applied Pharmacology, vol. 255, no. 2, pp. 193-199, 2011.

[37] R. K. Zalups, "Molecular interactions with mercury in the kidney," Pharmacological Reviews, vol. 52, no. 1, pp. 113-143, 2000.

[38] T. W. Clarkson and L. Magos, "The toxicology of mercury and its chemical compounds," Critical Reviews in Toxicology, vol. 36, no. 8, pp. 609-662, 2006.

[39] J. P. K. Rooney, "The role of thiols, dithiols, nutritional factors and interacting ligands in the toxicology of mercury," Toxicology, vol. 234, no. 3, pp. 145-156, 2007.

[40] World Health Organization, Methyl Mercury, vol. 1, International Progranme on Chemical Safety, Geneva, Switzerland, 1990.

[41] FDA- Food and Drug Administration. Thimerosal in Vaccines, Center of Biologics Evaluation and Research, 2008, http://www.fda.gov/Cber/vaccine/thimerosal.htm.

[42] G. Guzzi and C. A. M. La Porta, "Molecular mechanisms triggered by mercury," Toxicology, vol. 244, no. 1, pp. 1-12, 2008.

[43] T. W. Clarkson, "The three modern faces of mercury," Environmental Health Perspectives, vol. 110, no. 1, pp. 11-23, 2002.

[44] C. L. Johnson, "Mercury in the environment: sources, toxicities, and prevention of exposure," Pediatric Annals, vol. 33, no. 7, pp. 437-442, 2004.

[45] L. E. Davis, M. Kornfeld, H. S. Mooney et al., "Methylmercury poisoning: long-term clinical, radiological, toxicological, and pathological studies of an affected family," Annals of Neurology, vol. 35, no. 6, pp. 680-688, 1994.

[46] S. C. Alexandre, Avaliação de área contaminada por mercúrio total em descoberto [Dissertação de Mestrado], Programa de Pós-Graduação em Engenharia Civil. Universidade Federal de Viçosa, Minas Gerais, Brazil, 2006.

[47] P. W. Davidson, G. J. Myers, B. Weiss, C. F. Shamlaye, and C. Cox, "Prenatal methyl mercury exposure from fish consumption and child development: a review of evidence and perspectives from the Seychelles Child Development Study," NeuroToxicology, vol. 27, no. 6, pp. 1106-1109, 2006.

[48] S. Lindberg, R. Bullock, R. Ebinghaus et al., "A synthesis of progress and uncertainties in attributing the sources of mercury in deposition," Ambio, vol. 36, no. 1, pp. 19-32, 2007.

[49] D. W. Boening, "Ecological effects, transport, and fate of mercury: a general review," Chemosphere, vol. 40, no. 12, pp. 1335-1351, 2000.

[50] E. B. Swain, P. M. Jakus, G. Rice et al., "Socioeconomic consequences of mercury use and pollution," Ambio, vol. 36, no. 1, pp. 45-61, 2007.

[51] Environmental Protection Agency, Mercury Study Report to Congress, U.S. Environmental Protection Agency, Washington, DC, USA, 1997.

[52] J. C. Hansen and G. Danscher, "Organic mercury: an environmental threat to the health of dietary-exposed societies?" Reviews on Environmental Health, vol. 12, no. 2, pp. 107-116, 1997.

[53] F. A. Azevedo and A. M. Chasin, As Bases Toxicológicas da Ecotoxicologia, São Carlos: RiMa, Atheneu/InterTox, São Paulo, Brazil, 2003.

[54] C. C. Bridges and R. K. Zalups, "Transport of inorganic mercury and methylmercury in target tissues and organs," Journal of Toxicology and Environmental Health-Part B, vol. 13, no. 5, pp. 385-410, 2010. 
[55] M. Roulet, M. Lucotte, R. Canuel et al., "Distribution and partition of total mercury in waters of the Tapajos River Basin, Brazilian Amazon," Science of the Total Environment, vol. 213, no. 1-3, pp. 203-211, 1998.

[56] M. Roulet, M. Lucotte, J. R. D. Guimarães, and I. Rheault, "Methylmercury in water, seston, and epiphyton of an Amazonian river and its floodplain, Tapajos River, Brazil," Science of the Total Environment, vol. 261, no. 1-3, pp. 43-59, 2000.

[57] J. G. Dórea, R. C. Marques, and K. G. Brandão, "Neonate exposure to thimerosal mercury from hepatitis B vaccines," American Journal of Perinatology, vol. 26, no. 7, pp. 523-527, 2009.

[58] S. Asano, K. Eto, E. Kurisaki et al., "Acute inorganic mercury vapor inhalation poisoning," Pathology International, vol. 50, no. 3, pp. 169-174, 2000.

[59] R. K. Zalups and L. H. Lash, "Advances in understanding the renal transport and toxicity of mercury," Journal of Toxicology and Environmental Health, vol. 42, no. 1, pp. 1-44, 1994.

[60] F. A. Azevedo and A. A. M. Chasin, Bases Toxicologicas da Ecotoxicologia, São Carlos: RiMa, Atheneu/InterTox, São Paulo, Brazil, 2003.

[61] JECFA, "Methylmercury. Summary and conclusions of the 67thThe Joint FAO/WHO Expert Committee on Food Additives. Geneva, World Health Organization, International Programme on Chemical Safety," WHO Technical Report Series 940, 2006, http://www.who.int/foodsafety/chem/en/.

[62] K. R. Mahaffey, "Mercury exposure: medical and public health issues," Transactions of the American Clinical and Climatological Association, vol. 116, pp. 127-154, 2005.

[63] C. Zavariz and D. M. Glina, "Clinico-neuro-psychological evaluation of workers exposed to metallic mercury in the electric lamp industry," Revista de Saude Publica, vol. 26, no. 5, pp. 356-365, 1992.

[64] T. W. Clarkson, "The three modern faces of mercury," Environmental Health Perspectives, vol. 110, no. 1, pp. 11-23, 2002.

[65] C. Peterson, "Medical slang in Rio de Janeiro, Brasil," Cadernos de saúde pública/Ministério da Saúde, Fundação Oswaldo Cruz, Escola Nacional de Saúde Pública, vol. 14, no. 4, pp. 671-682, 1998.

[66] B. H. Choi, K. H. Cho, and L. W. Lapham, "Effects of methylmercury on human fetal neurons and astrocytes in vitro: a time-lapse cinematographic, phase and electron microscopic study," Environmental Research, vol. 24, no. 1, pp. 61-74, 1981.

[67] N. Ballatori and T. W. Clarkson, "Biliary secretion of glutathione and of glutathione-metal complexes," Fundamental and Applied Toxicology, vol. 5, no. 5, pp. 816-831, 1985.

[68] E. Brodkin, R. Copes, A. Mattman, J. Kennedy, R. Kling, and A. Yassi, "Lead and mercury exposures: interpretation and action," CMAJ, vol. 176, no. 1, pp. 59-63, 2007.

[69] National Academy of Sciences, Toxicological Effects of Methylmercury, National Research Council, Washington, DC, USA, 2000.

[70] A. H. Stern, "A revised probabilistic estimate of the maternal methyl mercury intake dose corresponding to a measured cord blood mercury concentration," Environmental Health Perspectives, vol. 113, no. 2, pp. 155-163, 2005.

[71] M. Gupta, J. K. Bansal, and C. M. Khanna, "Blood mercury in workers exposed to the preparation of mercury cadmium telluride layers on cadmium telluride base," Industrial Health, vol. 34, no. 4, pp. 421-425, 1996.

[72] C. Chen, L. Qu, B. Li et al., "Increased oxidative DNA damage, as assessed by urinary 8 -hydroxy-2'-deoxyguanosine concentrations, and serum redox status in persons exposed to mercury," Clinical Chemistry, vol. 51, no. 4, pp. 759-767, 2005.

[73] W. R. Bastos, J. P. O. Gomes, R. C. Oliveira et al., "Mercury in the environment and riverside population in the Madeira River Basin, Amazon, Brazil," Science of the Total Environment, vol. 368, no. 1, pp. 344-351, 2006.

[74] S. Halbach, "Combined estimation of mercury species released from amalgam," Journal of Dental Research, vol. 74, no. 4, pp. 1103-1109, 1995.

[75] W. McKelvey, R. C. Gwynn, N. Jeffery et al., "A biomonitoring study of lead, cadmium, and mercury in the blood of New York City adults," Environmental Health Perspectives, vol. 115, no. 10, pp. 1435-1441, 2007.

[76] P. Grandjean, P. Weihe, R. F. White et al., "Cognitive deficit in 7-year-old children with prenatal exposure to methylmercury," Neurotoxicology and Teratology, vol. 19, no. 6, pp. 417-428, 1997.

[77] K. A. Graeme and C. V. Pollack, "Heavy metal toxicity, part I: arsenic and mercury," Journal of Emergency Medicine, vol. 16, no. 1, pp. 45-56, 1998.

[78] P. Grandjean, E. Budtz-Jørgensen, R. F. White et al., "Methylmercury exposure biomarkers as indicators of neurotoxicity in children aged 7 years," American Journal of Epidemiology, vol. 150, no. 3, pp. 301-305, 1999.

[79] P. R. Sager, M. Aschner, and P. M. Rodier, "Persistent, differential alterations in developing cerebellar cortex of male and female mice after methylmercury exposure," Brain Research, vol. 314, no. 1, pp. 1-11, 1984.

[80] T. Kishimoto, T. Oguri, and M. Tada, "Effect of methylmercury $\left(\mathrm{CH}_{3} \mathrm{HgCl}\right)$ injury on nitric oxide synthase (NOS) activity in cultured human umbilical vascular endothelial cells," Toxicology, vol. 103, no. 1, pp. 1-7, 1995.

[81] R. A. Ponce, T. J. Kavanagh, N. K. Mottet, S. G. Whittaker, and E. M. Faustman, "Effects of methyl mercury on the cell cycle of primary rat CNS cells in vitro," Toxicology and Applied Pharmacology, vol. 127, no. 1, pp. 83-90, 1994.

[82] B. H. Choi, K. H. Cho, and L. W. Lapham, "Effects of methylmercury on human fetal neurons and astrocytes in vitro: a time-lapse cinematographic, phase and electron microscopic study," Environmental Research, vol. 24, no. 1, pp. 61-74, 1981.

[83] A. F. Castoldi, S. Barni, I. Turin, C. Gandini, and L. Manzo, "Early acute necrosis, delayed apoptosis and cytoskeletal breakdown in cultured cerebellar granule neurons exposed to methylmercury," Journal of Neuroscience Research, vol. 59, no. 6, pp. 775-787, 2000.

[84] N. K. Mottet, M. E. Vahter, J. S. Charleston, and L. T. Friberg, "Metabolism of methylmercury in the brain and its toxicological significance," Metal Ions in Biological Systems, vol. 34, pp. 371-403, 1997.

[85] S. Yee and B. H. Choi, "Methylmercury poisoning induces oxidative stress in the mouse brain," Experimental and Molecular Pathology, vol. 60, no. 3, pp. 188-196, 1994.

[86] F. Weinsberg, U. Bickmeyer, and H. Wiegand, "Effects of inorganic mercury $\left(\mathrm{Hg}^{2+}\right)$ on calcium channel currents and catecholamine release from bovine chromaffin cells," Archives of Toxicology, vol. 69, no. 3, pp. 191-196, 1995.

[87] C. S. Huang and T. Narahashi, "Mercury chloride modulation of the GABA(A) receptor-channel complex in rat dorsal root ganglion neurons," Toxicology and Applied Pharmacology, vol. 140, no. 2, pp. 508-520, 1996.

[88] W. D. Atchison and T. Narahashi, "Methylmercury-induced depression of neuromuscular transmission in the rat," Neuro Toxicology, vol. 3, no. 3, pp. 37-50, 1982. 
[89] W. D. Atchison, "Extracellular calcium-dependent and independent effects of methylmercury on spontaneous and potassium-evoked release of acetylcholine at the neuromuscular junction," Journal of Pharmacology and Experimental Therapeutics, vol. 237, no. 2, pp. 672-680, 1986.

[90] S. Halbach, S. Vogt, W. Köhler et al., "Blood and urine mercury levels in adult amalgam patients of a randomized controlled trial: interaction of $\mathrm{Hg}$ species in erythrocytes," Environmental Research, vol. 107, no. 1, pp. 69-78, 2008.

[91] G. Sandborgh-Englund, C. G. Elinder, S. Langworth, A. Schütz, and J. Ekstrand, "Mercury in biological fluids after amalgam removal," Journal of Dental Research, vol. 77, no. 4, pp. 615-624, 1998.

[92] D. A. Geier and M. R. Geier, "An assessment of the impact of thimerosal on childhood neurodevelopmental disorders," Pediatric Rehabilitation, vol. 6, no. 2, pp. 97-102, 2003.

[93] C. Cox, T. W. Clarkson, D. O. Marsh, L. Amin-Zaki, S. Tikriti, and G. G. Myers, "Dose-response analysis of infants prenatally exposed to methyl mercury: an application of a single compartment model to single-strand hair analysis," Environmental Research, vol. 49, no. 2, pp. 318-332, 1989.

[94] S. Hussain, D. A. Rodgers, H. M. Duhart, and S. F. Ali, "Mercuric chloride-induced reactive oxygen species and its effect on antioxidant enzymes in different regions of rat brain," Journal of Environmental Science and Health-Part B, vol. 32, no. 3, pp. 395-409, 1997.

[95] J. R. Brawer, G. F. McCarthy, M. Gornitsky, D. Frankel, K. Mehindate, and H. M. Schipper, "Mercuric chloride induces a stress response in cultured astrocytes characterized by mitochondrial uptake of iron," NeuroToxicology, vol. 19, no. 6, pp. 767-776, 1998.

[96] M. Königsberg, N. E. López-Díazguerrero, L. Bucio, and M. C. Gutiérrez-Ruiz, "Uncoupling effect of mercuric chloride on mitochondria isolated from an hepatic cell line," Journal of Applied Toxicology, vol. 21, no. 4, pp. 323-329, 2001.

[97] L. Massaroni, E. M. Oliveira, I. Stefanon, and D. V. Vassallo, "Effects of mercury on the mechanical and electrical activity of the Langendorff-perfused rat heart," Brazilian Journal of Medical and Biological Research, vol. 25, no. 8, pp. 861-864, 1992.

[98] E. M. Oliveira, D. V. Vassallo, J. J. F. Sarkis, and J. G. Mill, "Mercury effects on the contractile activity of isolated heart muscle," Toxicology and Applied Pharmacology, vol. 128, no. 1, pp. 86-91, 1994.

[99] J. Y. Su and W. J. Chen, "The effects of methylmercury on isolated cardiac tissues," American Journal of Pathology, vol. 95, no. 3, pp. 753-764, 1979.

[100] S. Halbach, G. Schonsteiner, and W. Vierling, "The action of organic mercury compounds on the function of isolated mammalian heart muscle," European Journal of Pharmacology, vol. 167, no. 2, pp. 255-264, 1989.

[101] S. Halbach, "Mercury compounds: lipophilicity and toxic effects on isolated myocardial tissue," Archives of Toxicology, vol. 64, no. 4, pp. 315-319, 1990.

[102] H. M. Rhee and B. H. Choi, "Hemodynamic and electrophysiological effects of mercury in intact anesthetized rabbits and in isolated perfused hearts," Experimental and Molecular Pathology, vol. 50, no. 3, pp. 281-290, 1989.

[103] W. R. Bastos, J. P. O. Gomes, R. C. Oliveira et al., "Mercury in the environment and riverside population in the Madeira River Basin, Amazon, Brazil," Science of the Total Environment, vol. 368, no. 1, pp. 344-351, 2006.

[104] M. Fillion, D. Mergler, C. J. Sousa Passos, F. Larribe, M. Lemire, and J. R. D. Guimarães, "A preliminary study of mercury exposure and blood pressure in the Brazilian Amazon," Environmental Health, vol. 5, article 29, 2006.

[105] E. Guallar, M. I. Sanz-Gallardo, P. Van’T Veer et al., "Mercury, fish oils, and the risk of myocardial infarction," The New England Journal of Medicine, vol. 347, no. 22, pp. 1747-1754, 2002.

[106] K. Yoshizawa, E. B. Rimm, J. S. Morris et al., "Mercury and the risk of coronary heart disease in men," The New England Journal of Medicine, vol. 347, no. 22, pp. 1755-1760, 2002.

[107] M. C. Houston, "The role of mercury and cadmium heavy metals in vascular disease, hypertension, coronary heart disease, and myocardial infarction," Alternative Therapies in Health and Medicine, vol. 13, no. 2, pp. S128-S133, 2007.

[108] J. T. Salonen, K. Seppanen, K. Nyyssonen et al., "Intake of mercury from fish, lipid peroxidation, and the risk of myocardial infarction and coronary, cardiovascular, and any death in Eastern Finnish men," Circulation, vol. 91, no. 3, pp. 645-655, 1995.

[109] J. K. Virtanen, S. Voutilainen, T. H. Rissanen et al., "Mercury, fish oils, and risk of acute coronary events and cardiovascular disease, coronary heart disease, and all-cause mortality in men in Eastern Finland," Arteriosclerosis, Thrombosis, and Vascular Biology, vol. 25, no. 1, pp. 228-233, 2005.

[110] J. Hulthe and B. Fagerberg, "Circulating oxidized LDL is associated with subclinical atherosclerosis development and inflammatory cytokines (AIR study)," Arteriosclerosis, Thrombosis, and Vascular Biology, vol. 22, no. 7, pp. 11621167, 2002.

[111] S. Ehara, M. Ueda, T. Naruko et al., "Elevated levels of oxidized low density lipoprotein show a positive relationship with the severity of acute coronary syndromes," Circulation, vol. 103, no. 15, pp. 1955-1960, 2001.

[112] M. C. Gonzalvo, F. Gil, A. F. Hernández, E. Villanueva, and A. Pla, "Inhibition of paraoxonase activity in human liver microsomes by exposure to EDTA, metals and mercurials," Chemico-Biological Interactions, vol. 105, no. 3, pp. 169-179, 1997.

[113] M. Mackness and B. Mackness, "Paraoxonase 1 and atherosclerosis: is the gene or the protein more important?" Free Radical Biology and Medicine, vol. 37, no. 9, pp. 13171323, 2004.

[114] M. Farina, M. Aschner, and J. B. T. Rocha, "Oxidative stress in MeHg-induced neurotoxicity," Toxicology and Applied Pharmacology, vol. 256, no. 1, pp. 405-417, 2011.

[115] L. Flohé, "Glutathione peroxidase," Basic Life Sciences, vol. 49, pp. 663-668, 1988.

[116] J. R. Arthur, "The glutathione peroxidases," Cellular and Molecular Life Sciences, vol. 57, no. 13-14, pp. 1825-1835, 2000.

[117] R. Brigelius-Flohé, "Glutathione peroxidases and redoxregulated transcription factors," Biological Chemistry, vol. 387, no. 10-11, pp. 1329-1335, 2006.

[118] L. Magos and T. W. Clarkson, "Overview of the clinical toxicity of mercury," Annals of Clinical Biochemistry, vol. 43, no. 4, pp. 257-268, 2006.

[119] T. W. Clarkson, “The toxicology of mercury," Critical Reviews in Clinical Laboratory Sciences, vol. 34, no. 4, pp. 369-403, 1997.

[120] M. Valko, C. J. Rhodes, J. Moncol, M. Izakovic, and M. Mazur, "Free radicals, metals and antioxidants in oxidative stress-induced cancer," Chemico-Biological Interactions, vol. 160, no. 1, pp. 1-40, 2006.

[121] H. E. Ganther, "Interactions of vitamin E and selenium with mercury and silver," Annals of the New York Academy of Sciences, vol. 355, pp. 212-226, 1980. 
[122] S. I. Sherwani, S. Pabon, R. B. Patel et al., "Eicosanoid signaling and vascular dysfunction: methylmercury-induced phospholipase D activation in vascular endothelial cells," Cell Biochemistry and Biophysics. In press.

[123] L. J. Raymond and N. V. C. Ralston, "Mercury: selenuim interactions and health implications," Seychelles Medical and Dental Journal, vol. 7, no. 1, pp. 72-77, 2004.

[124] A. Naganuma, Y. Koyama, and N. Imura, "Behavior of methylmercury in mammalian erythrocytes," Toxicology and Applied Pharmacology, vol. 54, no. 3, pp. 405-410, 1980.

[125] J. Rungby and E. Ernst, "Experimentally induced lipid peroxidation after exposure to chromium, mercury or silver: interactions with carbon tetrachloride," Pharmacology and Toxicology, vol. 70, no. 3, pp. 205-207, 1992.

[126] L. V. Rossoni, S. M. C. Amaral, P. F. Vassallo et al., "Effects of mercury on the arterial blood pressure of anesthetized rats," Brazilian Journal of Medical and Biological Research, vol. 32, no. 8, pp. 989-997, 1999.

[127] A. C. Machado, A. S. Padilha, G. A. Wiggers, F. D. M. Siman, I. Stefanon, and D. V. Vassallo, "Small doses of mercury increase arterial pressure reactivity to phenylephrine in rats," Environmental Toxicology and Pharmacology, vol. 24, no. 2, pp. 92-97, 2007.

[128] L. Massaroni, E. M. Oliveira, I. Stefanon, and D. V. Vassallo, "Effects of mercury on the mechanical and electrical activity of the Langendorff-perfused rat heart," Brazilian Journal of Medical and Biological Research, vol. 25, no. 8, pp. 861-864, 1992.

[129] L. B. Furieri, M. Fioresi, R. F. R. Junior et al., "Exposure to low mercury concentration in vivo impairs myocardial contractile function," Toxicology and Applied Pharmacology, vol. 255, no. 2, pp. 193-199, 2011.

[130] L. Massaroni, L. V. Rossoni, S. M. C. Amaral, I. Stefanon, E. M. Oliveira, and D. V. Vassallo, "Haemodynamic and electrophysiological acute toxic effects of mercury in anaesthetized rats and in Langendorff perfused rat hearts," Pharmacological Research, vol. 32, no. 1-2, pp. 27-36, 1995.

[131] L. B. Furieri, M. Galán, M. S. Avendaño et al., "Endothelial dysfunction of rat coronary arteries after exposure to low concentrations of mercury is dependent on reactive oxygen species," British Journal of Pharmacology, vol. 162, no. 8, pp. 1819-1831, 2011.

[132] F. M. Pecanha, G. A. Wiggers, A. M. Briones et al., "The role of cyclooxygenase (COX)-2 derived prostanoids on vasoconstrictor responses to phenylephrine is increased by exposure to low mercury concentration," Journal of Physiology and Pharmacology, vol. 61, no. 1, pp. 29-36, 2010.

[133] G. A. Wiggers, F. M. Peçanha, A. M. Briones et al., "Low mercury concentrations cause oxidative stress and endothelial dysfunction in conductance and resistance arteries," American Journal of Physiology, vol. 295, no. 3, pp. H1033H1043, 2008.

[134] J. Blanco-Rivero, L. B. Furieri, D. V. Vassallo, M. Salaices, and G. Balfagón, "Chronic $\mathrm{HgCl}_{2}$ treatment increases vasoconstriction induced by electrical field stimulation: role of adrenergic and nitrergic innervation," Clinical Science, vol. 121, no. 8, pp. 331-341, 2011. 

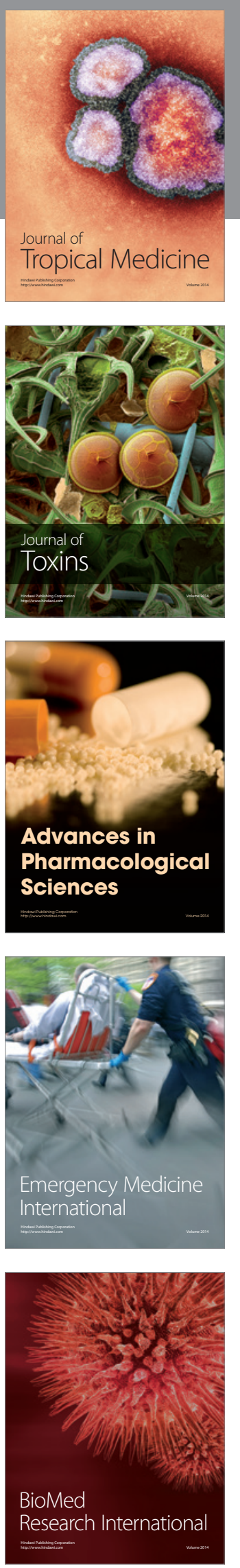
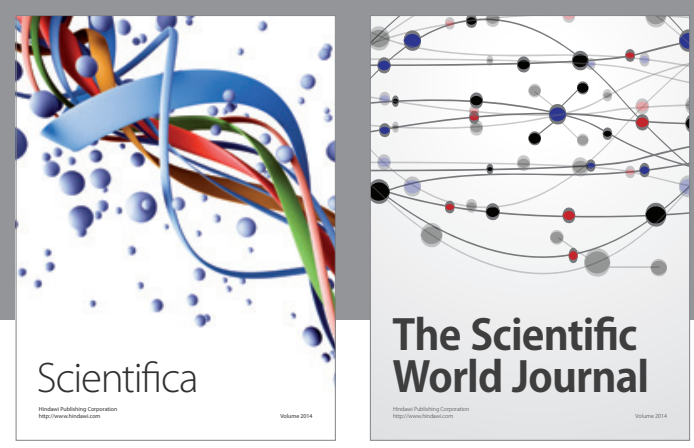

The Scientific World Journal
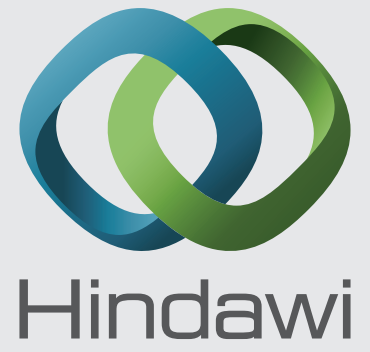

Submit your manuscripts at

http://www.hindawi.com
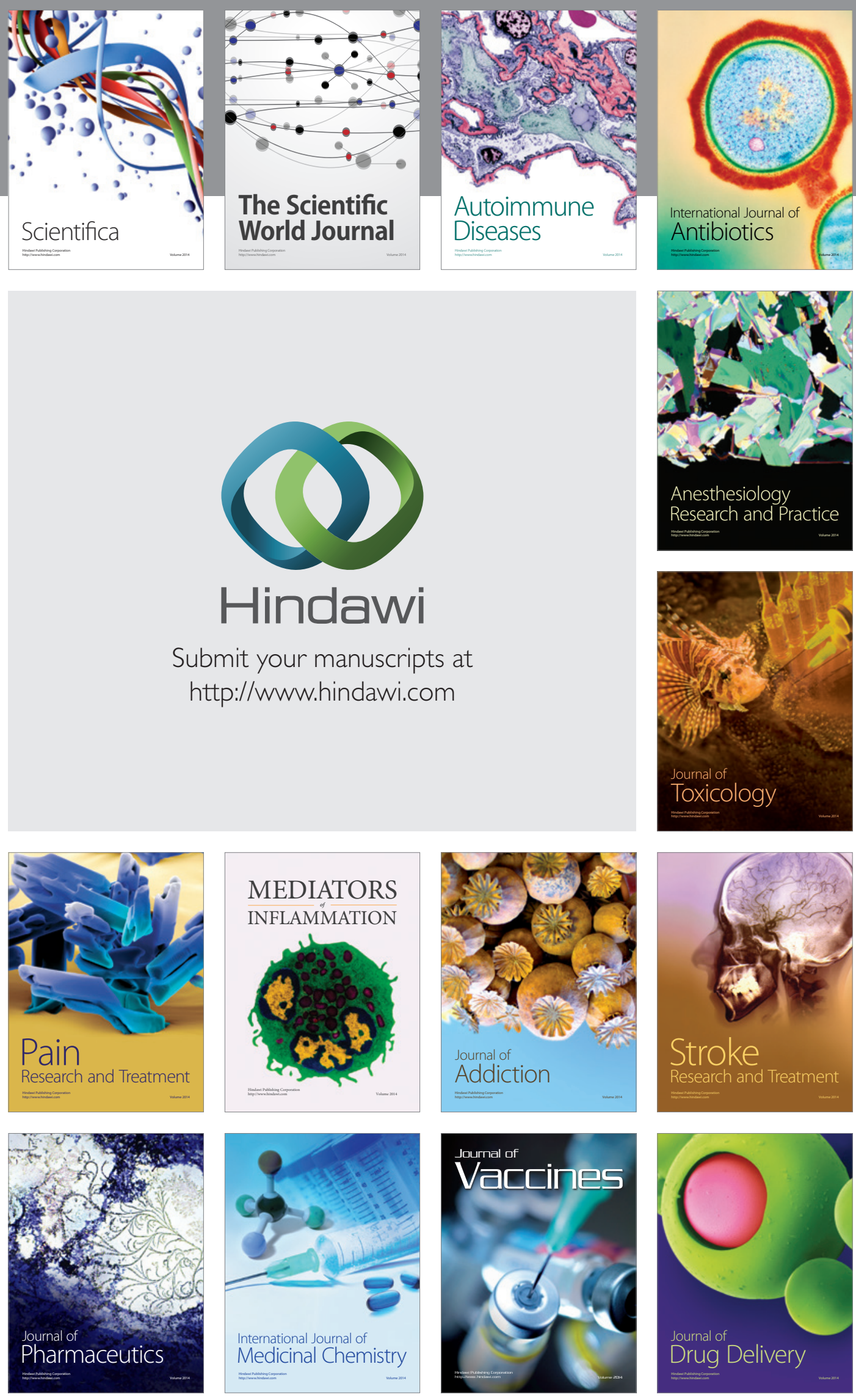